\title{
Estudo de balneabilidade em quatro praias do arquipélago de Fernando de Noronha
} baseado em análise de coliformes totais

\author{
Bathing study on four beaches of the Fernando de Noronha archipelago based on total coliform \\ analysis
}

Estudio de baños en cuatro playas del archipiélago de Fernando de Noronha basado en análisis de coliformes totales

Recebido: 24/08/2021 | Revisado: 29/08/2021 | Aceito: 30/08/2021 | Publicado: 02/09/2021

\author{
Múcio Luiz Banja Fernandes \\ ORCID: http://orcid.org/0000-0003-2156-860X \\ Instituto Avançado de Tecnologia e Inovação, Brasil \\ E-mail: mucio.banja@iati.org.br \\ Renata Laranjeiras Gouveia \\ ORCID: https://orcid.org/0000-0002-3691-0060 \\ Instituto Avançado de Tecnologia e Inovação, Brasil \\ E-mail: renata.laranjeiras@iati.org.br \\ Larissa Felix de Lucena \\ ORCID: https://orcid.org/0000-0002-1519-996X \\ Instituto Avançado de Tecnologia e Inovação, Brasil \\ E-mail: larissa.lucena@iati.org.br \\ Midiã da Silva Rodrigues \\ ORCID: https://orcid.org/0000-0002-9975-4886 \\ Instituto Avançado de Tecnologia e Inovação, Brasil \\ E-mail: midia.rodrigues@iati.org.br \\ Andréa Karla Pereira da Silva \\ ORCID: https://orcid.org/0000-0002-6961-2529 \\ Instituto Avançado de Tecnologia e Inovação, Brasil \\ E-mail: andrea.silva@iati.org.br \\ Nathália Maria Padilha da Rocha e Silva \\ ORCID: https://orcid.org/0000-0003-0999-7663 \\ Instituto Avançado de Tecnologia e Inovação, Brasil \\ E-mail: Nathalia.padilha@iati.org.br
}

\begin{abstract}
Resumo
Com o objetivo de desenvolver atividades de monitoramento ambiental na ilha de Fernando de Noronha, a Companhia de Eletrificação de Pernambuco está desenvolvendo uma série de estudos sobre água, solo e qualidade do ar. Para este fim, o Instituto Avançado de Tecnologia e Inovação promoveu campanhas na ilha para coletas de dados. Com recursos do Programa de Pesquisa e desenvolvimento da Agência Nacional de energia Elétrica foram programadas seis viagens durante os anos de 2018 e 2019 para estudos de qualidade ambiental. Foram escolhidas quatro praias para coletas, sendo duas na porção do mar de dentro da ilha e duas no mar de fora. As amostras de estudos de coliformes foram processadas ainda na ilha, por meio de testes rápidos com inoculação em Placas $3 \mathrm{M}^{\mathrm{TM}}$ Petrifilm ${ }^{\mathrm{TM}}$ e cultivo em estufa microbiológica. Paralelamente foram coletadas amostras da água para estudos de parâmetros físico-químicos básicos. Do ponto de vista das análises de coliformes as praias podem ser classificadas como balneabilidade Excelente, conforme indicação da Resolução $\mathrm{n}^{\circ} 20$ do CONAMA. O maior valor registrado atingiu acima de 5.000 NMP/100g- ${ }^{1}$ para a praia do Porto, em período de alta estação turística. Embora os valores registrados estejam, no geral, em condições muito boas, estudos de coliformes presentes no sedimento arenoso seriam complementares importantes para um diagnóstico mais preciso sobre a qualidade ambiental das praias estudadas.
\end{abstract}

Palavras-chave: Balneabilidade; Coliformes; Fernando de Noronha; Pernambuco.

\begin{abstract}
Environmental monitoring activities have been developed on the island of Fernando de Noronha, the Pernambuco Electrification Company is carrying out a series of studies on water, soil and air quality. For this, the Advanced Institute of Technology and Innovation promoted campaigns on the island to collect water quality data. With resources from the National Electric Energy Agency's Research and Development Program, six trips were scheduled during 2018 and 2019 for environmental quality studies. Four beaches were chosen for collections, two in the protected portion of the island and two in the area facing the oceanic zone. The samples from coliform studies were processed while on the island, through rapid tests with inoculation in $3 \mathrm{M}^{\mathrm{TM}}$ Petrifilm ${ }^{\mathrm{TM}}$ Plates and cultivation in a microbiological greenhouse.
\end{abstract}


At the same time, water samples were collected for studies of basic physicochemical parameters. Regarding the analysis of coliforms, the beaches can be classified as Excellent bathing, as indicated in Resolution 20 of CONAMA. The highest value recorded reached above 5,000 NMP/100g-1 for Porto beach, in a period of high tourist season. Although the recorded values are, in general, in very good condition, studies of coliforms present in the sandy sediment would be important complementary for a more accurate diagnosis of the environmental quality of the studied beaches. Keywords: Bathing; Coliforms; Fernando de Noronha; Pernambuco.

\section{Resumen}

Se han desarrollado actividades de monitoreo ambiental en la isla de Fernando de Noronha, la Compañía de Electrificación de Pernambuco está realizando una serie de estudios sobre la calidad del agua, suelo y aire. Para ello, el Instituto Avanzado de Tecnología e Innovación impulsó campañas en la isla para recopilar datos de calidad del agua. Con recursos del Programa de Investigación y Desarrollo de la Agencia Nacional de Energía Eléctrica, se programaron seis viajes durante 2018 y 2019 para estudios de calidad ambiental. Se eligieron cuatro playas para la recolección, dos en la porción protegida de la isla y dos en el área frente a la zona oceánica. Las muestras de los estudios de coliformes se procesaron mientras estaban en la isla, mediante pruebas rápidas con inoculación en placas $3 \mathrm{M}^{\text {TM }}$ Petrifilm ${ }^{\text {TM }}$ y cultivo en invernadero microbiológico. Al mismo tiempo, se recolectaron muestras de agua para estudios de parámetros fisicoquímicos básicos. En cuanto al análisis de coliformes, las playas se pueden catalogar como de Excelente baño, como se indica en la Resolución 20 de CONAMA. El valor más alto registrado superó los 5.000 NMP / 100g-1 para la playa de Porto, en un período de alta temporada turística. Si bien los valores registrados se encuentran, en general, en muy buen estado, los estudios de coliformes presentes en el sedimento arenoso serían complementarios importantes para un diagnóstico más certero de la calidad ambiental de las playas estudiadas.

Palabras clave: Baño; Coliformes; Fernando de Noronha; Pernambuco.

\section{Introdução}

A Ilha de Fernando de Noronha está localizada no Atlântico Sul, sendo considerada uma das melhores opções turísticas no litoral do Brasil. Em função disso, existe grande procura turística e rotatividade humana que exploram suas praias bem preservadas. Embora localizada em zona oceânica, existem moradores na ilha que condicionam a presença de estruturas urbanizadas, que demandam moradias, sistemas hoteleiros, comércios e outras atividades. A partir da infraestrutura urbana é necessária a presença de uma Estação de Tratamento de Resíduos, que gera material residual, descartado no sistema marinho. Em função dessa situação, foi implantado um estudo de balneabilidade em quatro praias da ilha, dentro do Programa de Monitoramento Ambiental da qualidade da água implementado a partir do Projeto Otimização Multiobjetivo de Recursos Energéticos Distribuídos visando Sustentabilidade e Confiabilidade em Microrredes Isoladas incluindo Sistema de Armazenamento de Energia com Baterias, implantado na Usina Tubarão de produção de energia, gerenciada pela Companhia de Eletrificação de Pernambuco.

O principal objetivo da pesquisa foi identificar a qualidade de ambientes marinhos de uso diretos pelos moradores locais e turistas, usando quatro praias para amostragens de balneabilidade por meio de estudos de coliformes. Os coliformes pertencem a uma família de bactérias, denominada por Enterobacteriaceae, e distribuída por 4 géneros: Citrobacter, Enterobacter, Escherichia e Klebsiella. Estes microrganismos estão presentes nos solos, plantas e animais, e representam aproximadamente $10 \%$ dos microrganismos presentes no intestino humano e de outros animais. Incluem ainda um outro grupo de microrganismos, denominados por coliformes fecais, que têm como principal origem o trato intestinal de animais de sangue quente, inclusive o Homem.

Neste caso, a pesquisa analisou o meio ambiente aquático para fonte de investigações. Para Lima (2013), infelizmente nem sempre a qualidade desta água é adequada para atividades recreativas. Provavelmente este problema é devido ao lançamento de esgoto nas praias diretamente, ou indiretamente através das bacias hidrográficas que deságuam nas praias que apresentam microorganismos que, segundo Poté et al (2009), são os coliformes fecais, E. coli e Enterococos são reportados como bactérias indicadoras de depósitos fecais. Para Souza et al (2017) Essas bactérias atuam como indicadores de poluição fecal por estarem naturalmente presentes no trato intestinal de animais e serem eliminadas em grande quantidade nas fezes. O ensaio de coliforme fecal verifica a presença e o número de bactérias de origem fecal na amostra de água da praia. Esta bactéria pode ser veículo de 
transmissão de doenças como a hepatite ou agente causador de problemas gastrointestinais. Além disso, a presença de coliformes fecais na água de praia, indica que esta pode ter sido contaminada com água de esgoto, que pode trazer outras doenças, caso o usuário da praia venha a ingerir a água. O maior risco, neste caso, é da população infantil.

Em função das atividades humanas a presença de bactérias nas praias tende a se elevar. Por isso, a implementação de programas de monitoramento como ferramenta de acompanhamento deve ser frequentemente implantada em áreas de altas atividades turísticas. Nos estudos de Reche et al (2010), percebe-se a indicação de implementação do monitoramento da qualidade da água, em paralelo com as avaliações de impactos ambientais, provocados pela presença ou proliferação de organismos indesejáveis, devem ser promovidas de acordo com as características próprias de cada local. No Brasil a Resolução CONAMA 430/2011, dispõe sobre a classificação de corpos d'água e diretrizes ambientais para seu enquadramento, utiliza os coliformes termotolerantes como padrão de qualidade microbiológica. Assim, este estudo é uma primeira oportunidade de estudar o nível de balneabilidade em quatro praias da Ilha de Fernando de Noronha.

\section{Metodologia}

A pesquisa segue a técnica exploratória buscando descobertas, com elucidação de fenômenos ou a explicação daqueles que não eram aceitos apesar de evidentes. Este método segue os conceitos indicativos de Gonçalves (2014), apresentando a eficiência de resultados com discussão com outros relatos. Foram coletadas 24 amostras em quatro praias da Ilha de Fernando de Noronha, sendo duas posicionadas geograficamente na área do "mar de fora" do Sueste e Caieiras) e duas na região do "mar de dentro" (Praia do Boldró e Praia do Porto) (Figura 1). Considerou-se períodos relacionados com as chuvas e estiagem para a região do Arquipélago de Fernando de Noronha. Os procedimentos para avaliação da balneabilidade seguiram instruções descritas no Artigo $26^{\circ}$. da Resolução CONAMA n ${ }^{\circ}$ 20, que define a qualidade da água nas categorias Excelente, Muito Boa, Satisfatória e Imprópria. As coletas foram realizadas quadrimestralmente entre os anos de 2018 e 2019. As amostras coletadas foram armazenadas em recipientes da cor âmbar de 150ml e transportados imediatamente para o laboratório de campo. Seguindo o indicativo de Marquezi et al (2010) utilizou-se o método de amostras rápidas, visto que nos casos em que as técnicas rápidas forem equivalentes à metodologia convencional, dá-se preferência ao uso dos primeiros testes, por serem mais rápidos, práticos e de menor custo. Este método é evidenciado por Fernandes \& Goes (2015) que reforçam que análises rápidas, com prazo de até 24 horas preserva a qualidade das colônias a serem verificadas. No laboratório foram pipetados $1 \mathrm{ml}$ da amostra para inoculação no meio de cultura em placa Placa $3 \mathrm{M}^{\mathrm{TM}}$ Petrifilm ${ }^{\mathrm{TM}}$ para Contagem Rápida de Coliformes. Em seguida as placas de meio de culturas, com as amostras, foram colocadas numa mini-estufa para incubação de testes microbiológicos por um prazo de 24 horas numa temperatura média de $40^{\circ} \mathrm{C}$. Foram analisadas as presenças de coliformes totais nas placas, por meio de contagem em câmera de contagem de coliformes e os resultados da contagem foram multiplicados por 1.000 (um mil). As colônias representaram a presença de coliformes totais. 
Figura 1. Localização das estações de coletas.

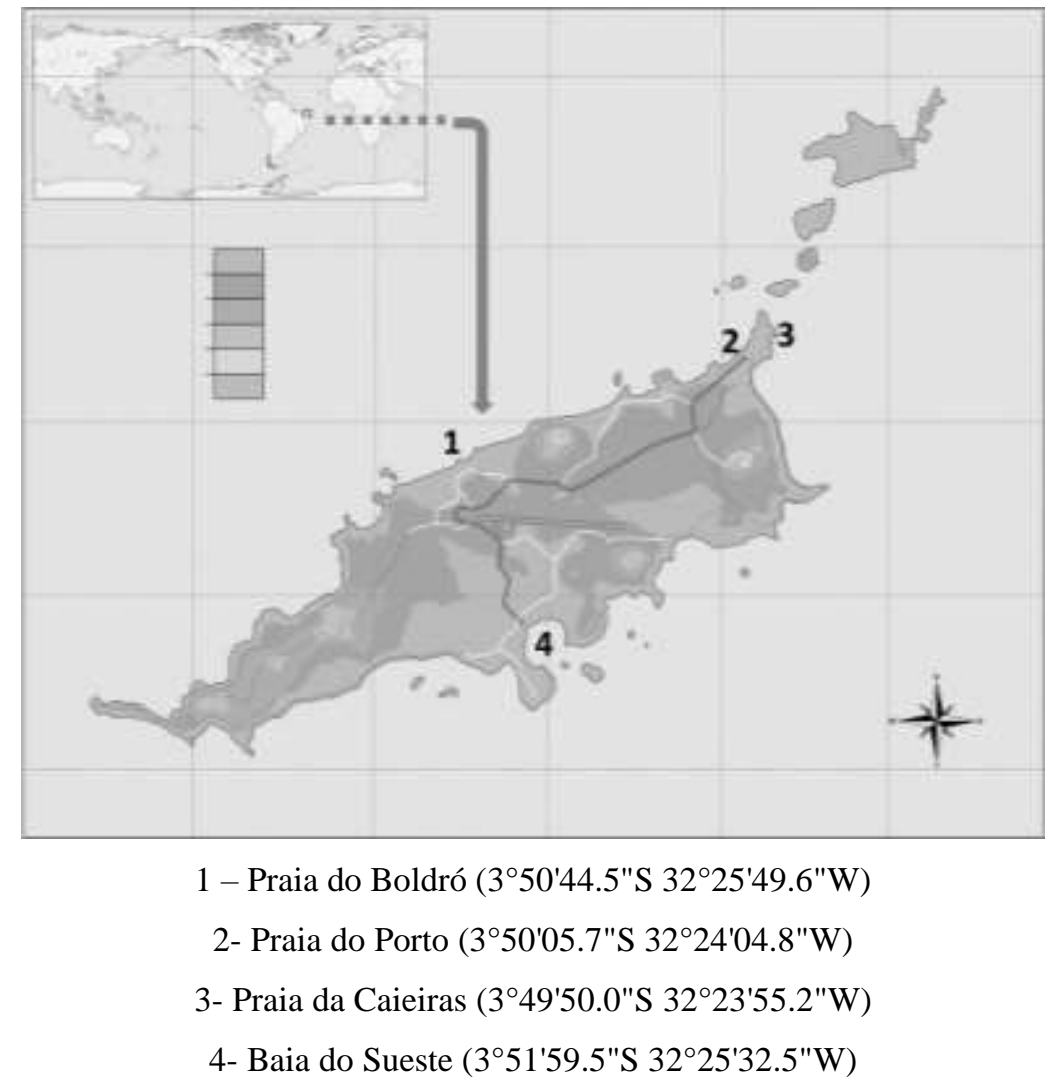

Fonte: Autores.

Além das coletas de amostras para estudos dos coliformes, foram analisados seis parâmetros hidrológicos para estudos comparativos das estações de coletas. Parâmetros como salinidade, temperatura da água, pH, Oxigênio dissolvido, Nitrogênio amoniacal e condutividade.

Foram realizados estudos comparativos entre a presença dos coliformes e as variações dos parâmetros hidrológicos. Para Lescreck et al (2016), o ensaio de pH, é um indicador do nível de acidez da água. Caso a água da praia esteja com o pH fora da faixa determinada pela Resolução CONAMA no . 20, o usuário da região de praia corre o risco de sofrer algum tipo de irritação da pele ou olhos. Daneluz \& Tessaro (2015) afirmam que o valor do pH é importante, pois apresenta forte relação com o crescimento bacteriano e, para a maioria das bactérias, o pH ótimo para seu desenvolvimento oscila entre 6,5 e 7,5.

Para o ensaio de coliforme fecal, a Resolução CONAMA $n^{\circ} 20$, determina que pelo menos $80 \%$ das amostras analisadas apresentem uma contagem de bactérias inferior a 1000 por $100 \mathrm{ml}$ de amostra, para que a balneabilidade da praia seja considerada satisfatória. Para o ensaio de $\mathrm{pH}$ é estabelecido uma faixa de variação, que vai de 5 a 8,5, dentro da qual o $\mathrm{pH}$ pode variar, sem risco para a balneabilidade da praia. Nos resultados foi levado em consideração a descrição de Zilli et al. (2003), que se referem à presença de coliformes em amostras ambientais como indicadores da qualidade do solo e da água para aspectos de sanidade no meio ambiente. Segundo Reche et al (2010) o Conselho Nacional do Meio Ambiente (CONAMA), resolução nº 357 , de 17 de março de 2005, designa coliformes termotolerantes como bactérias Gram-negativas, em forma de bacilos, naturalmente depositadas no meio ambiente aquático.

\section{Resultados e Discussão}

Foram levantadas seis amostras em cada uma das praias estudadas. No mesmo momento das coletas foram aferidos dados hidrológicos nos pontos de coletas (Tabela 1). Sousa et al. (2004) observaram que variações no número de coliformes está 
relacionada a interação de fatores físicos, químicos e biológicos. No geral os padrões relacionados às características físicoquímicas não demonstraram resultados fora dos padrões estabelecidos pela Resolução CONAMA 350/2004. Entre os valores correlacionados aos resultados de coliformes, considerou-se os estudos do potencial de Hidrogênio (Figura 2). Em todas as coletas o pH prevaleceu neutro ou alcalino, na grande maioria dos pontos. Os resultados encontrados para salinidade correspondem aos valores típicos de regiões marinhas.

Tabela 1. Resultados de análises hidrológicas das estações de coletas em Fernando de Noronha.

\begin{tabular}{|c|c|c|c|c|c|c|c|}
\hline PONTO & $\begin{array}{c}\text { MÊS } \\
\text { COLETA }\end{array}$ & TEMP & COND & OD & NIT.AMON. & pH & SAL. \\
\hline \multirow{7}{*}{ Praia do Boldró } & Mar/18 & 30 & 398 & 4,5 & 0,19 & 8,0 & 34 \\
\hline & Ago/l8 & 29,2 & 511 & 7,9 & 0 & 7,9 & 45 \\
\hline & Nov/18 & 28,7 & 511 & 6,5 & 0,05 & 7,6 & 41 \\
\hline & Fev/19 & 33,1 & 453 & 7,2 & 0,5 & 7,8 & 38 \\
\hline & Jun/19 & 29,8 & 520 & 9,7 & 0,15 & 5,1 & 31 \\
\hline & Set/19 & 25,5 & 657 & 6,4 & 0,03 & 7,2 & 41 \\
\hline & Dez/19 & 28,2 & 650 & 7,0 & 0,08 & 7,8 & 35 \\
\hline \multirow{7}{*}{ Praia do Porto } & Mar/18 & 28,8 & 370 & 3,7 & 0,09 & 8,2 & 29 \\
\hline & Ago/18 & 26,9 & 483 & 9,6 & 0,14 & 8,6 & 38 \\
\hline & Nov/18 & 27,9 & 511 & 8,1 & 0,04 & 8,3 & 40 \\
\hline & Fev/19 & 30,5 & 137 & 7,9 & 0,1 & 8,2 & 36 \\
\hline & Jun/19 & 29,9 & 452 & 6,0 & 0 & 7,8 & 36 \\
\hline & Set/19 & 26,6 & 531 & 7,6 & 0,04 & 8,1 & 39 \\
\hline & Dez/19 & 28,9 & 480 & 7,2 & 0,01 & 8,0 & 38 \\
\hline \multirow{7}{*}{ Ponta da Caieiras } & Mar/18 & 32,9 & 370 & 5,0 & 0,09 & 8,5 & 36 \\
\hline & Ago/18 & 27,1 & 483 & 9,8 & 0 & 8,7 & 37 \\
\hline & Nov/18 & 28,2 & 483 & 7,9 & 0,05 & 8,2 & 38 \\
\hline & Fev/19 & 31,5 & 398 & 5,1 & 0,7 & 8,4 & 35 \\
\hline & Jun/19 & 29,7 & 510 & 9,3 & 0 & 7,3 & 41 \\
\hline & Set/19 & 26,3 & 657 & 8,1 & 0,01 & 7,9 & 41 \\
\hline & Dez/19 & 29,2 & 602 & 7,5 & 0,04 & 7,8 & 38 \\
\hline \multirow{7}{*}{ Baia do Sueste } & Mar/l8 & 27,9 & 483 & 4,2 & 0,19 & 8,0 & 28 \\
\hline & Ago/l8 & 28,2 & 425 & 6,8 & 0,15 & 8,4 & 38 \\
\hline & Nov/18 & 30,4 & 453 & 7,8 & 0,03 & 8,5 & 38 \\
\hline & Fev/19 & 32,4 & 453 & 9,3 & 0,25 & 8,3 & 36 \\
\hline & Jun/19 & 28,7 & 452 & 9,2 & 0 & 8,2 & 41 \\
\hline & Set/19 & 28,3 & 510 & 6,4 & 0,01 & 8 & 39 \\
\hline & Dez/19 & 30,8 & 490 & 7,4 & 0 & 8,1 & 38 \\
\hline
\end{tabular}

Fonte: Autores. 
Figura 2. Relação dos resultados de coliformes totais com os valores de $\mathrm{pH}$ dos pontos de coletas.

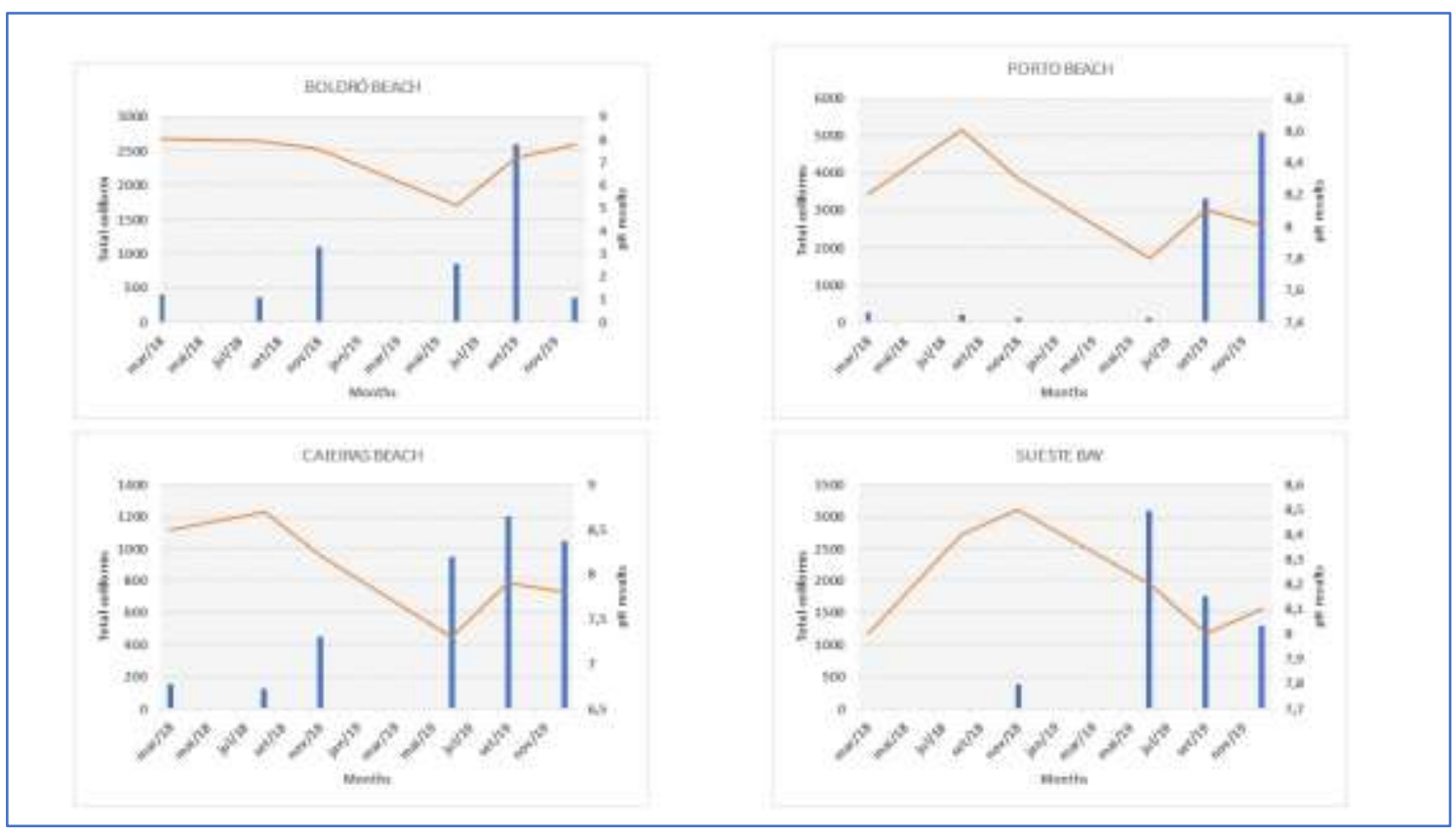

Fonte: Autores.

Os resultados obtidos mostram que a praia do Boldró apresentou uma tendência a manter valores mais elevados para a presença de coliformes totais (Tabela 2). No entanto, o maior valor registrado foi na amostra de dezembro de 2019 para a prai a do Porto, com um valor de $5.100 \mathrm{NMP} / 100 \mathrm{~g}^{-1}$. Este valor foi detectado num período de estiagem na região, com temperaturas em médias mais elevadas.

Tabela 2. Valores encontrados para coliformes totais durante as campanhas nos quatro pontos de coletas na Ilha de Fernando de Noronha.

\begin{tabular}{ccccccc}
\hline LOCAIS DE COLETAS & \multicolumn{5}{c}{ COLIFORMES TOTAIS (NMP/100mL) } \\
\cline { 2 - 7 } & Mar/18 & Ago/18 & Nov/18 & Jun/19 & Set/19 & Dez/19 \\
\hline Praia do Boldró & 400 & 360 & 1.090 & 850 & 2.600 & 350 \\
\hline Praia do Porto & 250 & 185 & 120 & 100 & 3.300 & 5.100 \\
\hline Ponta da Caierias & 150 & 120 & 450 & 950 & 1.200 & 1.050 \\
\hline Baia do Sueste & 0 & 0 & 368 & 3.100 & 1.750 & 1.300 \\
\hline
\end{tabular}

Fonte: Autores.

Os resultados de coliformes totais mostram resultados, geralmente, num padrão excelente de qualidade de água. Sazonalmente os padrões nas quatro praias se comportaram semelhentes, com um comportammento que mostram valores mais elevados no período de estiagem (Figura 3). Corroborando com estes resultados Tiefenthaler et al. (2008) constataram que os níveis populacionais de bactérias indicadoras de contaminação fecal (Escherichia coli, Enterococos e coliformes totais), em relação à sazonalidade, foram significativamente mais elevados durante o verão. Por outro lado, o período de chuvas pode influenciar sobre valores mais elevados dos coliformes, como atestam Kolm \& Andretta (2003), quando avaliaram a influência da maré sobre as bactérias no litoral do Paraná e concluíram que bactérias heterotróficas aeróbias, coliformes totais e E. coli 
apresentaram correlação direta com a matéria orgânica particulada e a pluviosidade. Com isso, atesta-se que não existe um indicador ideal de qualidade sanitária da água, e sim os que se aproximam dos requisitos exigidos, como afirmam Bettega et al. (2006) e Neto et al. (2009).

Figura 3. Resultados obtidos para os coliformes totais ao longo do período de pesquisas nas quatro praias.

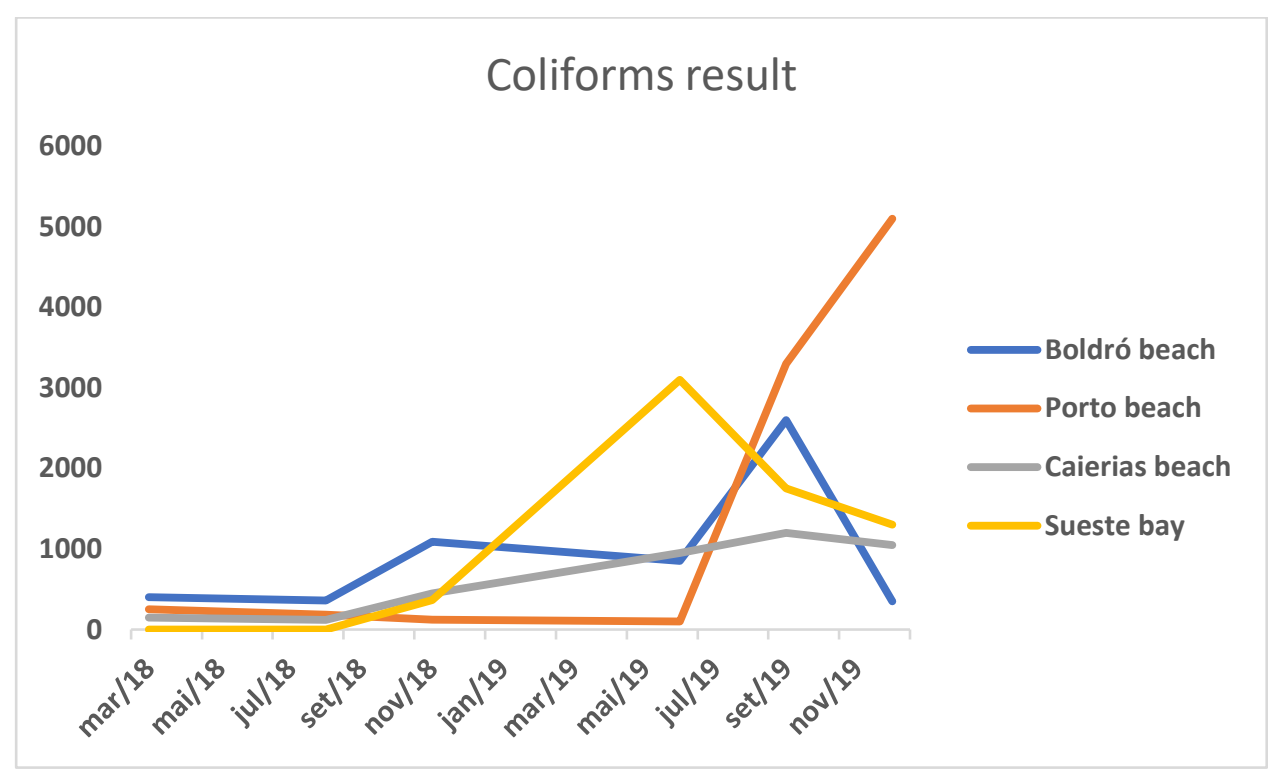

Fonte: Autores.

Não foi possível encontrar um padrão para as praias localizadas no mar de dentro como a praia do Boldró e a praia do Porto. Algumas causas podem justificar a diferença de resultado verificada nesses dois pontos tão próximos. Primeiro. Os estudos de Carlucci e Pramer (1960) apontaram para a variável salinidade como um dos principais fatores de ocorrências de coliformes termotolerantes, alertando que estes organismos não possuem de maneira geral uma regulação osmótica, fator primordial para ambientes salinos.

Embora os resultados para o meio aquático tenham apresentado resultados satisfatórios nas praias estudadas, praias consideradas satisfatórias o ambiente arenoso faz parte do complexo praial, devendo ser considerado também para a qualidade ambiental. Estudos de Lamparelli et al (2003) alertam para a forte relação de ocorrência de coliformes entre o ambiente aquático e arenoso, prevendo que em águas com limites excessivos de coliformes devem ter suas areias interditadas para uso humano.

Discute-se a necessidade de estudar a presença de coliformes na faixa de areia das praias do Porto e Baia do Sueste para conclusões mais precisas em relação a qualidade de balneabilidade. Esta indicação é reforçada nos estudos de Bonilla et al (2007), quando apontam que existe uma maior concentração de coliformes na porção de areia do que na água, investigando praias do litoral da Flórida, corroborado pelos resultados de Pinto, Pereira e Oliveira (2012), no município de São Vicente, São Paulo, mostrando que houve diferenças significativas entre as densidades de bactérias encontradas na água e na areia. Pinto (2010), investigou a Praia do Boqueirão, Santos, e encontrou o número máximo de 330.000 NMP/100g- ${ }^{1}$ (número mais provável por $100 \mathrm{~g}$ de areia).

Toda região da ilha de Fernando de Noronha possui intensas atividades turísticas em todo seu litoral. Lima (2013), alerta que o fato de que ao mesmo tempo o turismo se utiliza dos recursos naturais, tem potencial para causar grandes impactos ambientais, promovidos pela prática do visitante e pelas atividades da estrutura de serviços que se formam no entorno desta atividade. Segundo Alves et al., (2008), ações antrópicas são as principais responsáveis pela diminuição da qualidade da água, 
mesmo ocorrendo eventuais fenômenos naturais que possam comprometê-la. Para Alves et al (2018), em consequência das ações humanas a qualidade da água tem sofrido forte influência, tornando-se muitas vezes imprópria para o uso direto.

Além dos possíveis impactos provocados pela atividade turística, Berg et al (2013) informam que cursos de água contaminados por esgotos domésticos, ao atingirem as águas das praias, podem expor os banhistas a bactérias, vírus e protozoários. Águas balneárias que estejam fora de padrões de sanidade apresentam a possibilidade de contrair diversas doenças e até a morte. Os microrganismos predominantes nesses ambientes são responsáveis pela transmissão, aos banhistas, de doenças de veiculação hídrica tais como: gastrenterite, hepatite A, cólera, febre tifoide, entre outras. A presença de microrganismos patogênicos na água geralmente é decorrente da poluição por fezes humanas e de animais, provenientes de águas residuárias (Gonzalez et al, 1982). Por isso, torna-se sensato corroborar com Lescreck et al (2016), que reforça a necessidade de estudos baseados em evidências epidemiológicas de exposição e análises de risco microbiológico, para o estabelecimento de padrões de qualidade e implantação de políticas públicas para monitoramento e controle da qualidade sanitária das praias.

\section{Conclusões}

Os estudos de coliformes em quatro ambientes da ilha de Fernando de Noronha mostrou um padrão de balneabilidade classificado entre Excelente e Muito Boa para três praias. Somente numa oportunidade de coleta que o nível Satisfatório foi verificado para a praia do Porto na amostra de novembro do ano 2019. No geral, os valores com maior frequência de coliformes está associado a praia do Boldró. É importante lembrar que tanto a praia do Porto, como a praia do Boldró estão localizadas na região da ilha conhecida como "mar de dentro", reforçando o caso de que é na praia do Boldró onde os resíduos da única estação de tratamento de esgotos da ilha são despejados, através do veículo hídrico conhecido como Riacho do Boldró.

Embora esses estudos iniciais apontem para uma qualidade de balneabilidade de muito boa qualidade nos pontos investigados, sugere-se aprofundamento de estudos de qualidade das praias a partir de estudos relacionados aos coliformes do sedimento arenoso dessas praias, para uma conclusão mais precisa para a balneabilidade de cada praia estudada. Assim, tornase imprescindível novos investimentos em pesquisas sobre balneabilidade em outras áreas da ilha de Fernando de Noronha, contribuído para uma gestão cada vez mais sustentável na região.

\section{Referências}

Alves, E. C., Silva, C. F., Cossich, E. S., Tavares, C.R.G., Souza, E.E.F., Carniel, A. (2008). Avaliação da Qualidade da Água da Bacia do Rio Pirapó- Maringá, Estado do Paraná, Por Meio de Parâmetros Físicos, Químicos e Microbiológicos. Acta Science and Technology, Maringá, v. 30, n.1.

Alves, S. G. S., Ataide, C. D. G., Silva, J. X. (2018). Microbiológica de coliformes totais e termotolerantes em água de bebedouros de um parque público de Brasília, Distrito Federal. Rev. Cient. Sena Aires. 7(1): 12-17.

Berg, C. H., Guercio, M. J., Ulbricht, V. R. (2013). Indicadores De Balneabilidade: A Situação Brasileira E As Recomendações Da World Health Organization. Int. J. Knowl. Eng. Manag, Florianópolis, v. 2, n. 3, p. 83-101, jul./out.

Bettega, J. M. P. R., Machado, M. R., Presibella, M., Baniski, G., Barbosa, C.A. (2006). Métodos analíticos no controle microbiológico da água para consumo humano. Ciência e Agrotecnologia, 30: 950-954,

Bonilla, T. D., Nowosielski, K., Cuvelier M., Hartz, A., Green, M., Esiobu, N., Mccorquodale, D.S., Fleisher, J.M., Rogerson, A. (2007). Prevalence and distribution of fecal indicator organisms in South Florida beach sand and preliminary assessment of health effects associated with beach sand exposure. Marine Pollution Bulletin, v. 54, n. 9, p. 1472-1482.

Brasil (2001). Conselho Nacional do Meio Ambiente. Resolução CONAMA 274, de 29 de novembro de 2000. Define os critérios de balneabilidade em águas brasileiras. Diário Oficial da União, Brasília, DF, 25 jan. 2001. Seção 1, n. 18, p. 70-71.

Brasil. (2005) Conselho Nacional do Meio Ambiente. Resolução CONAMA 357, de 17 de março de 2005. Dispõe sobre a classificação dos corpos de água e diretrizes ambientais para o seu enquadramento. Diário Oficial da União, Brasília, DF, 18 mar 2005. Seção 1, n. 53, p. 58-63

Carlucci, A. F. \& Pramer, D. (1960). An Evaluation of Factors Affecting the Survoval of Escherichia Coli in Sea Water: Salinity, PH and Nutrients. Appl Microbiol. Jul; 8(4): 247-250.

Daneluz, D. \& Tessaro, D. (2015). Padrão físico-químico e microbiológico da água de nascentes e poços rasos de propriedades rurais da região sudoeste do Paraná. Arq. Inst. Biol., São Paulo, v.82 p. 1-5. 
Research, Society and Development, v. 10, n. 11, e302101119784, 2021

(CC BY 4.0) | ISSN 2525-3409 | DOI: http://dx.doi.org/10.33448/rsd-v10i11.19784

Fernandes, L. L. \& Gois, R.V. (2015) Avaliação das principais metodologias aplicadas às análises microbiológicas de água para consumo humano voltadas para a detecção de coliformes totais e termotolerantes. Revista Científica da Faculdade de Educação e Meio Ambiente 6(2): 49-64, jul-dez.

Gonçalves, H. A. (2005) Manual De Metodologia Da Pesquisa Cientifica. Avercamp: Rio de Janeiro. 144 p.

Lamparelli, C. C., Sato, M.I.Z., Bruni, A.C. (2003). A qualidade sanitária das águas das praias e sua correlação com a ocorrência de distúrbios gastrointestinais em banhistas. In: Congresso Brasileiro de Pesquisas Ambientais e Saúde. Santos: COPEC, 2003.

Lescreck, M. C., Petroni, R.G.G., Cortez, F.S., Santos, A.R., Coutinho, P.O., Pusceddu, F.H. (2016). Análise da qualidade sanitária da areia das praias de Santos, litoral do estado de São Paulo. Eng Sanit Ambient | v.21 n.4 | out/dez 2016|777-782.

Lima, R. C. (2013). Análise espaço-temporal da balneabilidade no litoral de João Pessoa e Cabedelo. Monografia (Bacharelado em Geografia) Universidade Federal da Paraíba. 71p.

Kolm, H. E. \& Andretta, L. (2003). Bacterioplancton in different tides of the Perequê tidal creek, Pontal do Sul, Paraná, Brazil. Brazilian Journal of Microbiology, 34: $97-103$

Marquezi, M. Z., Gallo, C. R., Dias, C. T. S. (2010). Comparação entre métodos para a análise de coliformes totais e E. coli em amostras de água. Rev Inst Adolfo Lutz. 2010; 69(3):291-6

Neto, J. M., Krüger, C. M., Dziedzic, M. (2009). Análise de indicadores ambientais no reservatório do Passaúna. Engenharia Sanitária Ambiental, 14: 205-214,

Pinto, K. C. (2010). Avaliação sanitária das águas e areias de praias da Baixada Santista, São Paulo. Dissertação (Mestrado em Saúde Ambiental) - Universidade de São Paulo, São Paulo.

Pinto, A. B., Pereira, C. R., Oliveira, A. J. F. C. (2012). Densidade de Enterococcus sp em águas recreacionais e areias de praias do município de São VicenteSP, Brasil e sua relação com parâmetros abióticos. O Mundo da Saúde, v. 36, n. 4, p. 587-593.

Poté, J., Goldscheider, N., Haller, L., Zopfi, J., Khajehnouri, F., Wildi, W. (2009). Origin and spatialtemporal distribution of fecal bacteria in a bay of Lake Geneva, Switzerland. Environmental Monitoring and Assessment, 154:337-348.

Reche, M. H. L. R., Pittol, M., Fiuza, L. M. (2010). Bactérias e bioindicadores de qualidade de águas de ecossistemas orizícolas da região sul do Brasil. Oecol. Aust., 14(2): 452-463.

Sousa, J. T. De., Van Haandel, A. C., Lima, E. P. Da. C., Henrique, I.N. (2004). Utilização de wetland construído no pós-tratamento de esgotos domésticos prétratados em reator UASB. Engenharia Sanitária Ambiental, 4: 285-290,

Souza, Q. S., Machado, C. M. S., Moura, L. O. G., Lima, F. S. (2017). Análise de coliformes totais e termotolerantes-fecais em diferentes pontos da sub-bacia do rio Poxim-Sergipe, Brasil. Agroforestalis News, v.2, n.2,

Tiefenthaler, L. L., Stein, D. E., Lyon, S. G. (2008). Fecal indicator bacteria (FIB) levels during dry weather from Southern California reference streams. Environmental Monitoring and Assessment, 155: 477-492,

Zilli, J. E., Rumjanek, N. G., Xavier, G. R., Coutinho, H. L. C., Neves, M. C. P. (2003). Diversidade microbiana como indicador da qualidade do solo. Cadernos de Ciência \& Tecnologia, 2: 391- 411. 